\title{
Purwarupa Kendali Lengan Dental Light dengan Isyarat Jari Berbasis Pengolahan Citra Digital
}

\author{
Muhammad Anis Al Hilmi*1, Agus Harjoko ${ }^{2}$ \\ ${ }^{1}$ Prodi Elektronika dan Instrumentasi, FMIPA UGM, Yogyakarta \\ ${ }^{2}$ Jurusan Ilmu Komputer dan Elektronika, FMIPA UGM, Yogyakarta \\ e-mail: *11alhilmi1@gmail.com, ${ }^{2}$ aharjoko@ugm.ac.id
}

\begin{abstract}
Abstrak
Dental light atau lampu sorot yang terdapat pada kursi praktik dokter gigi merupakan salah satu bagian penting pada dental chair. Dental light perlu diatur posisinya agar arah cahaya sorot sesuai kebutuhan dokter. Cara biasa untuk mengaturnya adalah dengan digerakkan dengan tangan secara langsung oleh dokter. Cara tersebut dirasakan cukup merepotkan dan mengurangi kesterilan tangan dokter karena harus menyentuh dental light secara langsung.

Dalam penelitian ini, masalah tersebut dicoba diselesaikan dengan teknologi pengolahan citra digital. Sebuah webcam digunakan untuk meng-capture citra. Kemudian citra diolah sampai mengenali isyarat jari, untuk kemudian dapat mengendalikan dental light. Pengenalan isyarat jari dalam penelitian ini menggunakan metode pemisahan objek dengan latar belakangnya. Range warna dari sarung tangan dokter dipakai sebagai acuan pengenalan objek tangan. Model warna yang dipakai adalah model HSV.

Dari 4 warna sarung tangan yang diuji, warna dengan hasil terbaik adalah warna kuning. Jarak optimal antara webcam dan posisi tangan adalah 55-65 cm. Waktu respon ratarata dari saat ada isyarat sampai lengan robot bergerak adalah 0,4-0,6 sekon. Dengan hasil penelitian ini diharapkan dokter tidak perlu lagi menyentuh langsung dental light sehingga pemakaiannya lebih mudah dan steril.
\end{abstract}

Kata kunci-dental light, lengan robot, pengolahan citra, range warna

Dental light or head-light that exists on a dental chair, is one of essenstial part of dental chair instruments. Dental light needs an appropriate positioning control to direct the light as needed by the dentist. The common way of controlling dental light is the dentist manually directing the lamp using their hand.

In this research, that problem is tried to be solved using digital image processing technology. A webcam is used to capture image, then the image is processed until yield a recognition result for finger gesture and then create an output to contol dental light. Finger gesture recognition is carried out by color filter method. The color range of dentist gloves is used as references to recognize the dentist's hand. The color model that used in this research is $H S V$.

From 4 colors of dentist gloves that tested, the best color is yellow. The optimum distance between webcam and hand position is $55-65 \mathrm{~cm}$. The average time response from the time that finger gesture appear until the prototype of arm robot moves is 0.4-0.6 second.

Keywords - dental light, arm robot, image processing, color range 


\section{PENDAHULUAN}

$\mathrm{D}$ alam dunia kedokteran gigi, dikenal suatu teknologi bernama dental chair. Dental chair adalah kursi periksa untuk pasien dokter gigi yang telah dilengkapi beberapa peralatan medis. Dental chair biasanya ditunjang oleh fasilitas listrik, gas, kompresor udara, aliran air, dan saluran pembuangan. Salah satu bagian penting dari dental chair adalah dental light. Dental light yaitu lampu yang disorotkan untuk menerangi bagian mulut pasien yang sedang diperiksa. Dental light ditopang oleh lengan berbahan metal yang memiliki sendi-sendi yang memungkinkannya melakukan beberapa gerakan, seperti tampak pada Gambar 1.

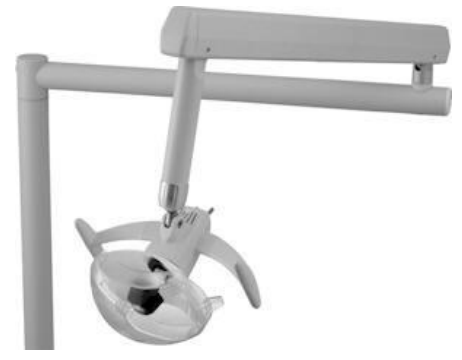

Gambar 1 Lengan dental light [1]

Dalam penggunaanya, dental light digerakkan menggunakan tangan sampai cahaya sorotnya dirasa sesuai dengan posisi periksa dokter. Namun, cara pengaturan tersebut dirasakan cukup merepotkan dan mengurangi kesterilan tangan dokter karena harus menyentuh langsung. Selain itu tidak semua dokter gigi didampingi asisten, padahal dalam melakukan praktiknya tangan dokter harus steril. Hal inilah yang melatarbelakangi penelitian ini.

\section{METODE PENELITIAN}

\subsection{Perancangan Sistem}

Sistem kendali dalam penelitian ini adalah berjenis open-loop dikarenakan output-nya tidak memberi efek/feedback ke sistem kontrol dan yang mengendalikan sepenuhnya adalah dokter gigi, seperti terlihat pada Gambar 2.

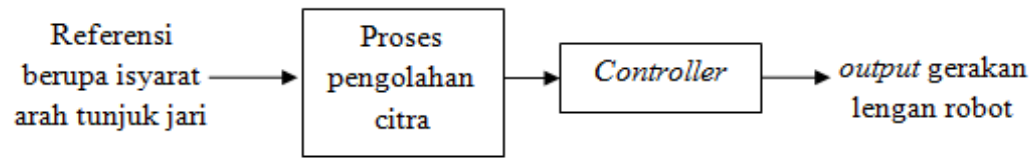

Gambar 2 Blok diagram sistem kendali

Masukan dari sistem kendali di atas berasal dari isyarat arah tunjuk jari dari dokter gigi, apakah menunjuk ke atas, ke bawah, ke kiri, atau ke kanan. Arah tunjuk digunakan sebagai input dirasakan memudahkan penggunaan karena hal itu mudah diingat dibandingkan dengan isyarat lain seperti menghitung jumlah jari. Kemudian untuk pengolahan citranya dibutuhkan prosesor yang mampu menjalankan program komputer. Sebagai controller, dibutuhkan piranti yang mudah digunakan pengguna dan juga mudah komunikasinya dengan laptop. Pada umumnya, untuk mengontrol sesuatu di luar komputer, yang biasa digunakan adalah protokol RS232/serial, namun karena di laptop sudah jarang dijumpai port serial, maka komunikasi yang dimungkinkan dan efisien adalah via USB. Sedangkan untuk modul controller itu sendiri membutuhkan hasil kerja yang baik dalam menggerakkan lengan robot, namun juga tidak terlalu kompleks.

IJEIS Vol. 2, No. 1, April 2012 : $45-56$ 
Sistem ini menggunakan webcam yang mengambil citra pola jari tangan. Pola tersebut didapat dari bentuk gerakan jari telunjuk atau jempol. Jari tersebut nantinya menunjuk ke suatu arah dari 4 pilihan arah, yakni atas, bawah, kiri, dan kanan seperti ditunjukkan pada Gambar 3.

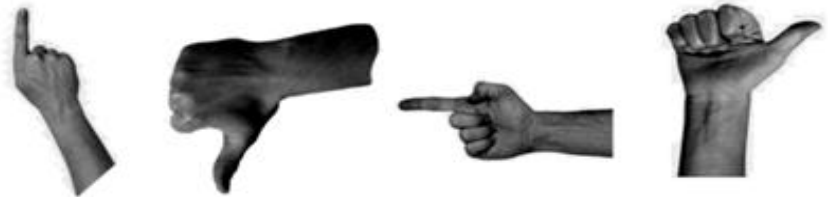

Gambar 3 Bentuk isyarat dari jari

Arah yang ditunjukkan oleh bentuk pola jari ini akan menjadi dasar masukan untuk gerakan lengan dental light tanpa menyentuh langsung. Pada dasarnya gerakan dental light ada 8, yaitu memutar ke atas, ke bawah, menggeleng ke kiri, menggeleng ke kanan, bergeser ke atas, ke bawah, berputar ke kiri, dan berputar ke kanan. Maka dari 4 arah yang menjadi input tadi, akan ditambahkan pedal yang bisa diinjak dokter (untuk mengontrol relay) guna memperbanyak variasi gerakan menjadi 2 kali lipatnya, menjadi total 8 gerakan. Hal ini agar dokter tidak perlu menghafal bentuk isyarat jari. Pemrosesan citra pola jari dilakukan menggunakan bahasa $\mathrm{C}++$ dengan library OpenCV. Di dalam program pemrosesan citra tersebut terdapat 5 jenis output, yaitu default, arah atas, arah bawah, arah kiri, dan arah kanan. Kemudian output tersebut dihubungkan dengan program PowerSwitch.

Program PowerSwitch, yang berjalan di atas OS Linux berguna mengendalikan board PowerSwitch yang terkoneksi dengan port USB komputer / laptop untuk mengeluarkan logika TTL 1 atau 0. Empat keluaran dari PowerSwitch lalu dihubungkan ke relay untuk diatur sambungannya ke papan PCB servo controller yang menerima 8 input. PCB servo controller menggerakkan lengan dental light jika ia mendapat masukan logika 0 atau dinamakan activelow. Masukan nilai ke servo controller didapat dari keluaran PowerSwitch.

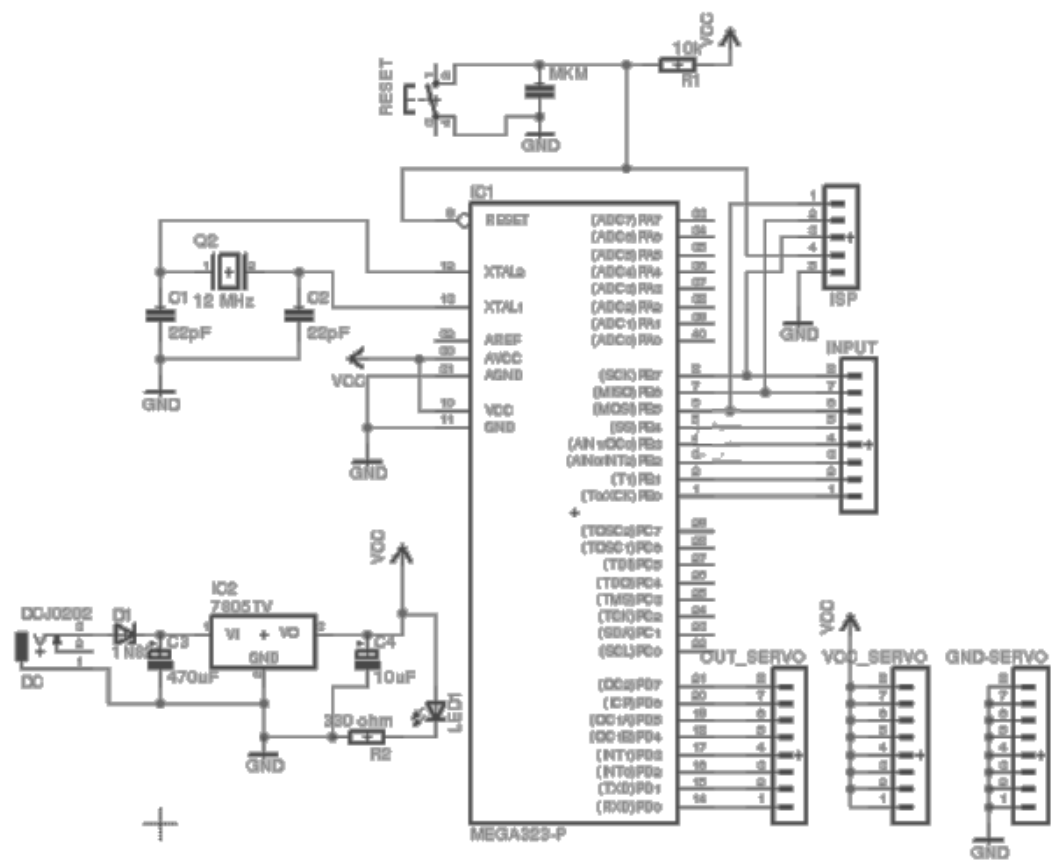

Gambar 4 Skema servo-controller

Motor servo bergerak mengikuti input dari pola deteksi arah jari. Ketika ada pola arah yang terdeteksi, maka servo controller akan mengirim sudut gerak lengan dan melakukan increment / penambahan sampai pola arah tidak ada lagi / kondisi default. Pada Gambar 5 ditunjukkan diagram blok dan diagram alir perancangan sistem secara keseluruhan. 


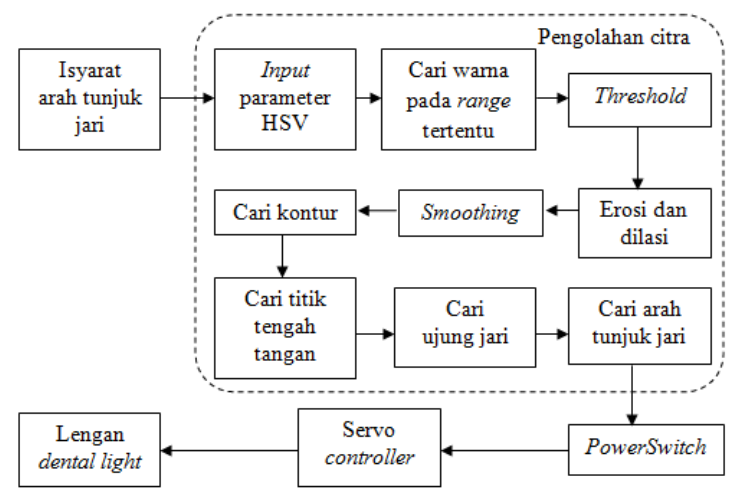

Gambar 5 Blok diagram sistem secara keseluruhan

\subsection{Perancangan Perangkat Lunak}

Dalam proses deteksi, ada beberapa langkah yang dilakukan, berikut adalah tahapan dalam mendeteksi jari :

1. Mengonversi citra hasil tangkapan webcam dari RGB ke HSV. Hal ini dilakukan untuk sedekat mungkin menyamai persepsi warna yang diterima indra manusia [2]. Juga agar lebih teliti dalam memilah nilai dari posisi warna objek, dalam hal ini adalah sarung tangan yang dipakai dokter.

2. Memeriksa citra dengan range warna tertentu dari sarung tangan dokter untuk mendapat bentuk dari tangan.

3. Setelah objek tangan terpilah warnanya dari latar belakang, maka citra selanjutnya dithreshold agar ada pemisahan secara tegas antara tangan dengan latar belakang.

4. Dari hasil di atas, ada beberapa derau yang dihasilkan, maka perlu dilakukan erosi dan dilasi agar derau hilang dan hasil deteksi maksimal [3].

5. Dari hasil dilasi, dilakukan smoothing agar citra menjadi halus.

6. Bentuk dari tangan dicari tepiannya saja untuk menghasilkan kontur tangan.

Setelah citra tangan berhasil dipilah dari latar belakangnya, selanjutnya dicari ke arah manakah isyarat jari menunjuk. Dalam penelitian Ho [4], dilakukan beberapa proses sampai menemukan arah tersebut. Cara menentukan arah isyarat jari dilakukan dengan melakukan perhitungan sudut antara 2 titik, $\mathrm{H}$ sebagai titik pusat tangan dan $\mathrm{P}$ sebagai ujung jari. Dari sana dapat ditentukan apakah arahnya ke atas, ke bawah, ke kanan, atau ke kiri.

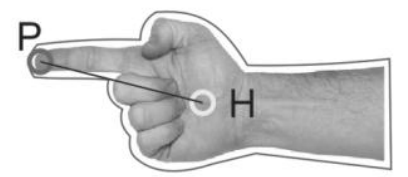

Gambar 6 Gambaran cara menentukan arah isyarat tangan

Titik tengah $\mathrm{H}$, diperoleh dari titik tengah dari keseluruhan objek tangan, sedangkan $\mathrm{P}$ adalah titik yang diciptakan oleh telunjuk atau jempol, juga Ox sebagai sumbu horizontal X. Setelah itu dapat dilakukan penghitungan $\operatorname{Cos}(\mathrm{HP}, \mathrm{Ox})$. Arah yang ditunjuk oleh jari ditentukan dengan aturan sebagai berikut :

1. Jika $\operatorname{Cos}(\mathrm{HP}, \mathrm{Ox})>0.7$, maka arah $=$ ke bawah.

2. Jika $\operatorname{Cos}(\mathrm{HP}, \mathrm{Ox})<-0.7$, maka arah $=$ ke atas.

3. Jika $-0.7<\operatorname{Cos}(\mathrm{HP}, \mathrm{Ox})<0.7$, dan H.y $<\mathrm{P} . \mathrm{y}$, arah $=$ kiri.

4. Jika $-0.7<\operatorname{Cos}(\mathrm{HP}, \mathrm{Ox})<0.7$, dan H.y $>$ P.y, $a r a h=$ kanan.

dimana H.y adalah nilai ordinat y dari titik H dan P.y adalah nilai ordinat dari titik P. 


\subsection{Perancangan Perangkat Keras}

Dalam mengatur gerakan lengan robot, 8 input/masukan menggunakan metode activelow. Ketika ada sinyal 0/GND maka program akan melakukan proses increment, selanjutnya nilai yang bertambah itu dikeluarkan ke bagian sinyal servo sebagai sudut putarnya. Nilai sudut dibatasi dari 0-255 untuk menghindari adanya perulangan loop program yang tidak perlu sehingga mengakibatkan gerakan lengan robot menjadi kacau.

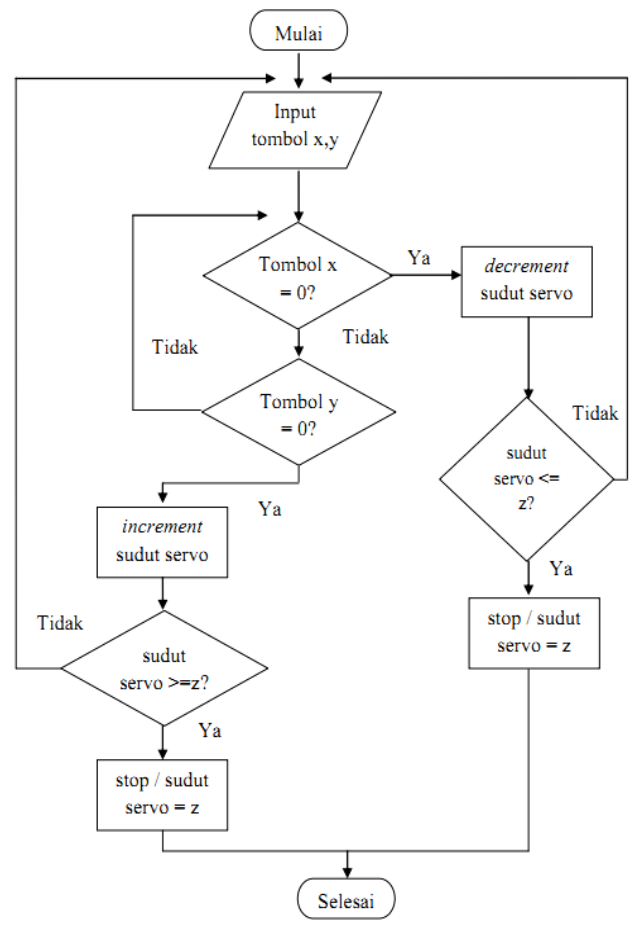

Gambar 7 Flowchart program kendali servo

Perangkat keras yang dipakai dalam sistem ini berupa webcam, board PowerSwitch, relay, pedal, dan board servo controller, serta lengan dental light yang disusun dari 4 motor servo. Webcam yang digunakan adalah Logitech $\mathrm{C} 170$ yang memiliki kualitas video yang cukup tajam yaitu maksimal 30 fps. Perangkat keras selanjutnya, board PowerSwitch (Gambar 8). Perangkat itu dihubungkan ke laptop dengan kabel USB. Output dari PowerSwitch dihubungkan ke relay yang sudah dilengkapi pedal.

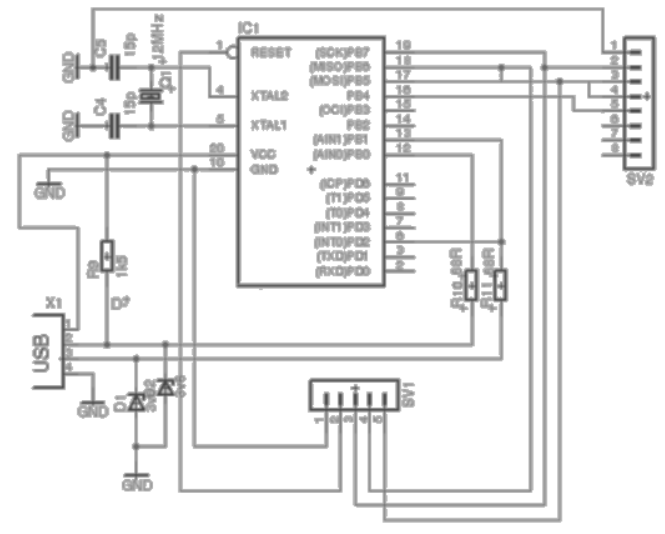

Gambar 8 Skema PowerSwitch 
Delapan keluaran dari relay terhubung ke papan pengendali gerakan motor servo. Pengendali ini mengontrol gerakan 4 motor servo yang sudut putar maksimalnya adalah $180^{\circ}$. Dari 4 motor servo, derajat kebebasan dari lengan dental light diperlihatkan pada Gambar 9. Derajat kebebasan merupakan sumbu pergerakan dari tiap motor servo.

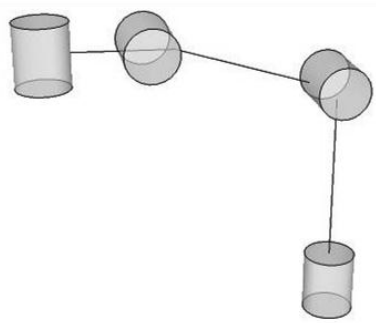

Gambar 9 Rancangan derajat kebebasan lengan dental light

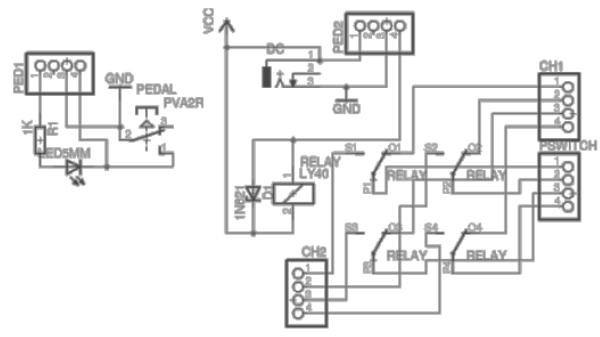

Gambar 10 Skema pedal dan relay

\subsection{Perancangan Pengujian}

Setelah seluruh perangkat lunak dan perangkat keras jadi dan telah diintegrasikan, diperlukan pengujian untuk mengetes sejauh mana kualitas dari penelitian ini. Tidak hanya masalah bisa atau tidak bisa menggerakkan lengan robot dengan isyarat jari, tapi ada beberapa pengujian kuantitatif yang perlu dilakukan. Pengujian tersebut diantaranya :

a. Pengujian warna sarung tangan

Karena dokter gigi dalam praktiknya menggunakan sarung tangan, maka objek yang akan dikenali warnanya adalah sarung tangan. Di pasaran, terdapat berbagai macam warna sarung tangan yang tersedia. Dari varian warna tersebut perlu diuji bagaimana karakteristik warna sarung tangan yang baik untuk dikenali dan menggerakkan lengan robot dental light.

b. Pengujian pengaruh intensitas cahaya

Dokter gigi melakukan praktik pada umumnya di dalam ruangan. Kondisi dari ruangan juga dapat bermacam-macam, yang paling berpengaruh terhadap kualitas citra adalah pengaruh intensitas cahaya dalam suatu ruangan. Maka pengaruh dari intensitas cahaya dalam ruangan juga perlu diuji, kondisi bagaimana yang menghasilkan pengontrolan yang baik.

c. Pengujian jarak

Jarak antara webcam dengan tangan perlu dites berapa jarak optimalnya. Perlu dicari, jarak berapakah yang menghasilkan pengontrolan lengan dental light yang baik dan sesuai isyarat yang diberikan.

d. Pengujian waktu respon

Waktu antara adanya isyarat dan kapan lengan robot meresponnya juga perlu diuji seberapa cepat. Jika responnya lambat, tentu akan menjadi masalah bagi dokter yang menggunakan sistem ini.

IJEIS Vol. 2, No. 1, April 2012: $45-56$ 
e. Pengujian ketepatan gerakan

Arah tunjuk dari jari dan gerakan dari lengan robot perlu diuji kesesuaiannya. Ini adalah esensi dari sistem kendali lengan dental light menggunakan isyarat jari.

\subsection{Implementasi Perangkat Lunak}

Perangkat lunak yang terdapat dalam sistem ini ada 4 bagian, yakni terdapat di dalam komputer berupa pengolahan citra untuk jari tangan, aplikasi PowerSwitch di commandline di mana keduanya berjalan di atas platform Linux Ubuntu. Perangkat lunak juga terdapat di board PowerSwitch, dan board servo controller.

Program pengolahan citra memproses citra yang ditangkap webcam seperti pada Gambar 12 dan setelah warna sarung tangan dipisahkan dari objek selainnya, maka hasilnya ditampilkan pada Gambar 13.
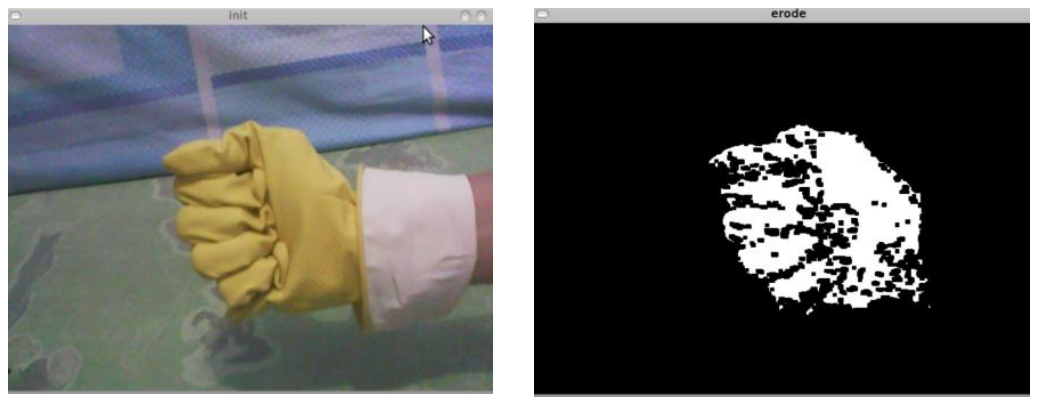

Gambar 12 Citra asli dari hasil capture dan citra setelah pemilahan warna

\subsection{Implementasi Perangkat Keras}

Perangkat keras yang digunakan pada penelitian ini terdiri dari beberapa bagian. PowerSwitch termasuk bagian yang menghubungkan perangkat lunak dengan perangkat keras. Ia berfungsi menerima perintah untuk menghidupkan atau mematikan channel yang dimilikinya. PowerSwitch yang belum dimodifikasi normalnya mengeluarkan output 5 volt untuk keadaan on dan 0 volt/GND jika off. PowerSwitch merupakan device sederhana yang menggunakan inti chip AVR untuk bisa berkomunikasi via USB tanpa chip tambahan seperti FTDI. Yang membuatnya memiliki kemampuan demikian karena di dalam AVR ditanam program/firmware V-USB atau virtual USB yang dikembangkan tim Object Development [5]. Untuk skema dari PowerSwitch, tidak berbeda dengan skema perangkat keras V-USB biasa, namun PowerSwitch memiliki 8 keluaran yang dapat diatur untuk on atau off.

Untuk mengatur gerakan servo, digunakan rangkaian sistem minimum ATmega32. Kebutuhan rangkaian ini standar saja, catu daya 5 volt yang diatur dengan bantuan regulator 7805, sumber clock eksternal berupa xtal $12 \mathrm{MHz}$, tombol untuk keperluan reset, 5 pin untuk ISP, 8 pin sebagai input, dan 8 lagi untuk output ke servo. Selain itu di dalam rangkaian terdapat VCC dan GND untuk motor servo. Port B diposisikan menjadi input sedangkan port D menjadi output. Empat Keluaran dari PowerSwitch diperbanyak variasinya menjadi 8 dengan relay 12 volt. Relay mempunyai 2 channel berbeda, pengaturan pemilihan channel-nya dilakukan dengan pedal sebagai sakelar. Pada pedal, diberi indikator berupa LED untuk menandai apakah sedang posisi on atau off. Antara PowerSwitch, servo controller, relay, dan pedal GND-nya disambungkan semua.

Webcam dipasang di bagian atas laptop, hal ini agar pengambilan citra stabil posisinya. Lengan dental light tersusun atas 4 servo dengan daya angkat maksimum $3 \mathrm{~kg}$. Servo pada lengan robot dibentuk dengan plastik yang dibengkokkan sedemikian rupa hingga menyerupai sendi. Perbandingan ukuran lengan dental light tidak seperti aslinya, hal ini karena keterbatasan daya angkat servo. Karena semakin panjang ukuran penghubung antar servo, maka torsi motor yang dibutuhkan semakin besar. Walau tidak sama dengan perbandingan ukuran asli, namun

Purwarupa Kendali Lengan Dental Light dengan Isyarat Jari... (Muhammad Anis AH.) 
tidak mengurangi esensi gerakan dari lengan dental light. Untuk merepresentasikan lampu dental light, dipasang juga LED yang menyerupai senter kecil. Pada Gambar 13 diperlihatkan gambar keseluruhan perangkat keras.

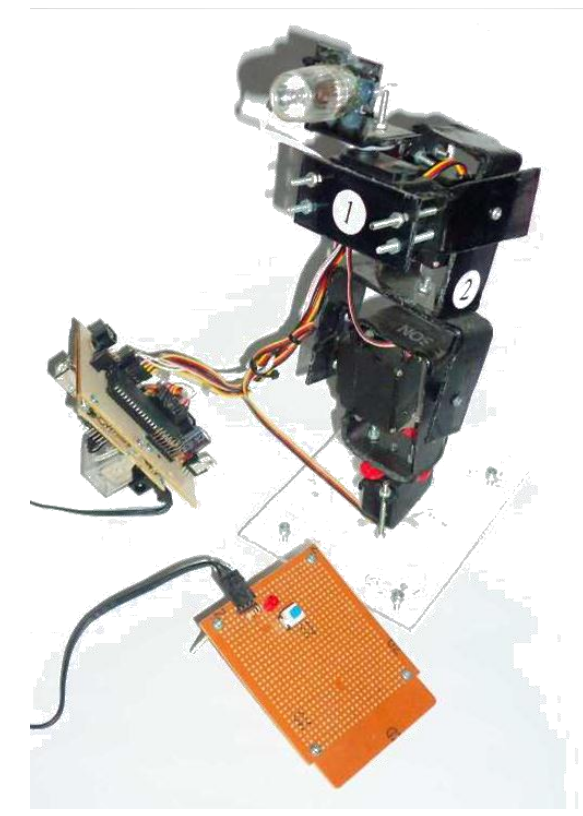

Gambar 13 Perangkat keras secara keseluruhan

\section{HASIL DAN PEMBAHASAN}

\subsection{Pengujian Warna Sarung Tangan}

Di pasaran, sarung tangan tersedia dalam beberapa warna. Pada intinya warna apapun tidak bermasalah untuk digunakan dokter gigi, asalkan bukan berwarna merah karena itu warna darah. Dan dari hasil pencarian di pasaran, warna sarung tangan yang biasa dipakai oleh dokter yang didapat, antara lain warna krem dan warna cyan. Namun, untuk menambah varian pengujian, didapat juga warna kuning dan warna oranye meskipun yang didapat dari pasaran bukan sarung tangan untuk dokter. Pada Gambar 14 diperlihatkan warna yang tersedia di pasaran.

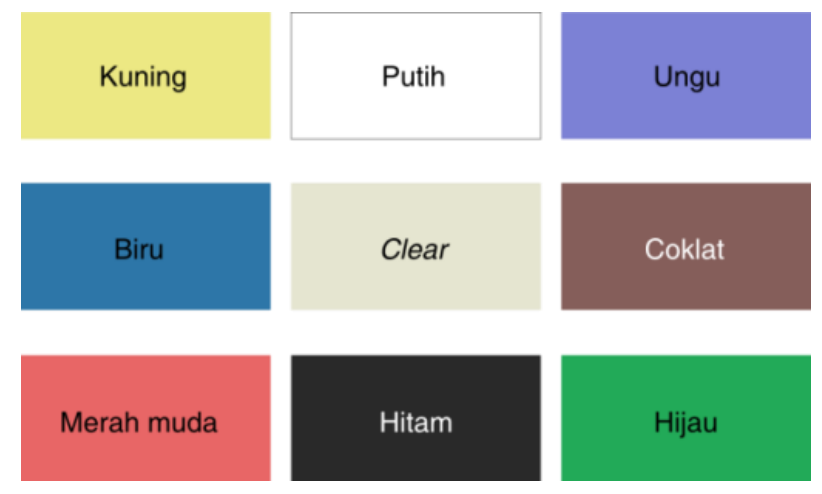

Gambar 14 Warna Sarung Tangan di Pasaran [6].

Pada Tabel 1 merupakan data percobaan warna sarung tangan yang berhasil didapat penulis.

IJEIS Vol. 2, No. 1, April 2012: $45-56$ 
Tabel 1 Hasil pengujian warna sarung tangan

\begin{tabular}{|c|c|c|c|c|c|c|}
\hline \multirow{2}{*}{ No. } & \multirow{2}{*}{ Warna } & \multirow{2}{*}{$\begin{array}{c}\text { Jumlah } \\
\text { Percobaan }\end{array}$} & \multicolumn{3}{|c|}{ Warna } & \multirow{2}{*}{ Ket } \\
\cline { 4 - 6 } & & & $\mathbf{H}$ & $\mathbf{S}$ & $\mathbf{V}$ & \\
\hline 1. & Kuning & 5 & $20-30$ & $100-255$ & $100-255$ & Sangat baik \\
\hline 2. & Cyan/biru & 5 & $40-90$ & $30-100$ & $120-255$ & Kurang \\
\hline 3. & Krem/clear & 5 & $2-50$ & $2-50$ & $100-255$ & Kurang \\
\hline 4. & Oranye & 5 & $0-10$ & $100-255$ & $100-250$ & Baik \\
\hline
\end{tabular}

Warna yang baik untuk digunakan adalah warna yang memiliki saturasi atau tingkat kemurnian yang tinggi ke warna primernya, dalam hal ini warna kuning sebagai yang terbaik. Warna cyan hasilnya kurang baik karena warnanya kurang pekat, sehingga ketika terkena cahaya warnanya bertambah cerah mendekati putih, sehingga dalam pemilahan warna, objek tangan yang didapat seringkali tidak utuh. Warna krem hasilnya kurang baik karena warnanya mendekati putih, sedangkan sering kali latar belakang dari citranya kebanyakan berwarna putih, sehingga menyulitkan pemilahan warna untuk mendeteksi objek tangan.

\subsection{Pengujian Pengaruh Intensitas Cahaya Ruangan}

Dalam pengolahan citra, intensitas cahaya sangat berpengaruh. Cahaya mempengaruhi hasil citra yang di-capture oleh kamera. Karena digunakan di kedokteran gigi, maka pengujian dilakukan di dalam ruangan, dengan asumsi praktik dokter gigi selalu di dalam ruangan.

Tabel 2 Hasil pengujian pengaruh intensitas cahaya

\begin{tabular}{|c|c|c|c|}
\hline No. & Kondisi & $\begin{array}{c}\text { Jumlah } \\
\text { Percobaan }\end{array}$ & Keterangan \\
\hline 1. & Gelap & 5 & Tidak bekerja \\
\hline 2. & Cahaya matahari & 5 & Bekerja baik \\
\hline 3. & Cahaya lampu & 5 & Bekerja baik \\
\hline
\end{tabular}

Pengujian dengan cahaya matahari dilakukan pada pukul 08.00 s.d. 12.00 di mana sinar matahari sudah dirasa cukup terang. Sedangkan pada pengujian di dalam ruangan dengan cahaya lampu dilakukan dengan lampu putih 15 watt, cukup untuk menerangi sebuah kamar $3 \times 3$ $\mathrm{m}^{2}$. Hasil pengujian pada aneka variasi intensitas cahaya menunjukkan asalkan ada cahaya dengan intensitas yang baik, dalam arti tidak terlalu gelap dan tidak terlalu terang, maka sistem dapat bekerja.

Pengaruh intensitas cahaya sangat terasa kepada hasil capture kamera, jika cahaya baik, maka warna dari sarung tangan dapat dideteksi juga dengan baik. Cahaya yang terlalu terang akan membuat warna sarung tangan yang ditangkap kamera menjadi lebih putih, sehingga malah dianggap bukan warna sarung tangan. Sama halnya pada kondisi gelap, warna sarung tangan cenderung lebih gelap dan banyak bayangan hitam, sehingga juga oleh program tidak dianggap sebagai warna sarung tangan.

\subsection{Pengujian Jarak Tangan}

Pengujian terhadap jarak tangan terhadap webcam perlu dilakukan karena perlu diketahui seberapa batas maksimum dan minimum jarak tangan dengan webcam yang masih bisa dideteksi sebagai isyarat. Jarak diuji dengan mendeteksi seberapa jauh dan seberapa dekat isyarat jari yang berada di depan webcam untuk bisa diproses. Hasil selengkapnya disajikan dalam Tabel 3. 
Tabel 3 Hasil pengujian jarak

\begin{tabular}{|c|c|c|c|}
\hline No. & $\begin{array}{c}\text { Jarak } \\
(\mathbf{c m})\end{array}$ & $\begin{array}{c}\text { Jumlah } \\
\text { Pengujian }\end{array}$ & Keterangan \\
\hline 1. & $>75$ & 5 & 0 terdeteksi, 5 error \\
\hline 2. & $65-75$ & 5 & 4 terdeteksi, 1 error \\
\hline 3. & $55-65$ & 5 & 5 terdeteksi, 0 error \\
\hline 4. & $45-55$ & 5 & 4 terdeteksi, 1 error \\
\hline 5. & $35-45$ & 5 & 4 terdeteksi, 1 error \\
\hline 6. & $25-35$ & 5 & 4 terdeteksi, 1 error \\
\hline 7. & $15-25$ & 5 & 0 terdeteksi, 5 error \\
\hline
\end{tabular}

Dari hasil pengujian jarak, terlihat bahwa jarak yang dapat dideteksi oleh program pengolahan citra adalah antara $25-75 \mathrm{~cm}$. Jarak optimal yang didapat dari pengujian menunjukkan pada rentang $55-65 \mathrm{~cm}$. Hal tersebut dipengaruhi oleh pengaturan listing program pengolahan citra. Di dalam kode program, terdapat batasan nilai panjang antara titik tengah tangan dengan ujung jari, yaitu " $r$ ". Maka, semakin jauh jarak tangan dari webcam, maka meskipun terdeteksi objeknya, jarak $r$ dianggap terlalu kecil sehingga tidak dipedulikan. Sebaliknya, ketika jarak tangan terlalu dekat, maka kamera tidak dapat menangkap citra tangan secara utuh, yang tertangkap hanyalah telapak tangan, tapi ujung jari tidak. Hal itu juga menyebabkan sistem tidak merespon apa-apa. Nilai $r$ ini dapat diatur dalam program sesuai kebutuhan. Adanya batasan jarak antara ujung jari dengan titik tengah tangan juga mencegah adanya salah deteksi, sistem hanya mau memproses warna sesuai yang ditentukan, tapi juga melihat apakah ada ujung jari yang menunjuk ke suatu arah atau tidak, jadi tidak asal ada suatu warna. Pengaturan ini sangat baik mengingat variasi warna pakaian dari pasien dokter gigi sangat banyak.

Adanya error dalam pendeteksian selain disebabkan jarak yang terlamapu dekat atau jauh, disebabkan juga kesalahan pembacaan akibat gerakan mendadak oleh tangan (yang sebelumnya di luar jangkauan capture kamera) masuk ke daerah yang terjangkau kamera. Maka, pemrosesan dilakukan terlalu dini, padahal tangan belum memberikan isyarat.

\subsection{Pengujian Waktu Respon Gerakan}

Pengujian terhadap waktu respon dimaksudkan untuk menguji seberapa jeda waktu mulai dari deteksi isyarat sampai lengan dental light bergerak. Pada Tabel 4 ditampilkan hasil dari pengujian respon menggunakan sarung tangan kuning dan pada jarak $55-65 \mathrm{~cm}$.

Tabel 4 Hasil Pengujian Waktu Respon

\begin{tabular}{|c|c|c|c|c|}
\hline No. & Arah & Jumlah Pengujian & Delay (sekon) & Waktu Rata-rata \\
\hline 1. & $\uparrow$ & $5 \mathrm{kali}$ & 0,$6 ; 1,0 ; 0,5 ; 0,4 ; 0,6$ & 0,6 sekon \\
\hline 2. & $\downarrow$ & $5 \mathrm{kali}$ & 0,$7 ; 0,5 ; 0,8 ; 0,3 ; 0,8$ & 0,6 sekon \\
\hline 3. & $\rightarrow$ & $5 \mathrm{kali}$ & 0,$4 ; 0,3 ; 0,4 ; 0,4 ; 0,5$ & 0,4 sekon \\
\hline 4 & $\leftarrow$ & $5 \mathrm{kali}$ & 0,$4 ; 0,5 ; 0,6 ; 0,4 ; 0,5$ & 0,5 sekon \\
\hline
\end{tabular}

Dibutuhkan 2 orang untuk melakukan pengujian ini, karena waktu yang perlu diukur sangat cepat. Dilakukan pengujian sebanyak 5 kali untuk memperbaik kevalidan data. Dari hasil uji, didapatkan bahwa jeda waktu respon gerak dari lengan dental light terhitung singkat, dibawah 1 sekon. Hal ini nampak pada semua arah tunjuk yang dilakukan tangan. Walaupun program pengolahan citra, program PowerSwitch, dan program pada servo controller terpisah, memiliki bahasa pemrograman yang berbeda dan meng-handle bagian masing-masing, terbukti dari pengujian ini, program-program tersebut dapat berkomunikasi dengan baik. Adanya jeda waktu ini disebabkan oleh proses pengolahan citra yang memproses frame tiap waktu dan juga kecepatan fps kamera. Adanya proses pengolahan dan deteksi memerlukan waktu untuk sampai pada kesimpulan gerakan. Namun dengan hasil yang baik ini, dapat dikatakan proses pengolahan citra dengan bahasa pemrograman $\mathrm{C}++$ dan pustaka pemrograman citra OpenCV

IJEIS Vol. 2, No. 1, April 2012: $45-56$ 
memiliki proses yang cepat dan hasil memuaskan.

Ketepatan dalam gerakan sangatlah penting, karena memang itulah hasil yang diharapkan dan paling esensial dalam penelitian ini. Pengujian ini dilakukan menggunakan sarung tangan kuning dan pada jarak $55-65 \mathrm{~cm}$. Pengujian dimaksudkan untuk mendapatkan data prosentase keberhasilan sistem kendali ini.

Tabel 5 Hasil Pengujian Ketepatan Gerakan

\begin{tabular}{|c|c|c|c|c|}
\hline No. & Arah & Jumlah Jari & Jumlah Pengujian & Keterangan \\
\hline 1. & $\uparrow$ & 1 & 5 & $5 x$ tepat \\
\hline 2. & $\downarrow$ & 1 & 5 & $5 x$ tepat \\
\hline 3. & $\rightarrow$ & 1 & 5 & $5 x$ tepat \\
\hline 4. & $\leftarrow$ & 1 & 5 & $5 x$ tepat \\
\hline 5. & $\uparrow$ & 2 & 5 & tidak stabil \\
\hline 6. & $\downarrow$ & 2 & 5 & tidak stabil \\
\hline 7. & $\rightarrow$ & 2 & 5 & tidak stabil \\
\hline 8. & $\leftarrow$ & 2 & 5 & tidak stabil \\
\hline 9. & $\uparrow$ & 3 & 5 & tidak ada respon \\
\hline 10. & $\downarrow$ & 3 & 5 & tidak ada respon \\
\hline 11. & $\rightarrow$ & 3 & 5 & tidak ada respon \\
\hline 12. & $\leftarrow$ & 3 & 5 & tidak ada respon \\
\hline 13. & $\uparrow$ & 4 & 5 & tidak ada respon \\
\hline 14. & $\downarrow$ & 4 & 5 & tidak ada respon \\
\hline 15. & $\rightarrow$ & 4 & 5 & tidak ada respon \\
\hline 16. & $\leftarrow$ & 5 & 5 & tidak ada respon \\
\hline
\end{tabular}

Proses pengujian dilakukan dengan cara :

1. Menggenggamkan tangan yang telah dipasang sarung tangan berwarna di depan kamera.

2. Membuat isyarat dengan menunjuk ke satu arah.

3. Mengamati arah gerakan yang dilakukan lengan robot.

Pengujian dilakukan selama 1 jam, dengan asumsi praktik dokter gigi rata-rata dilakukan dengan durasi seperti itu. Dari hasil pengujian ini nampak bahwa ketepatan dari gerakan lengan robot sudah baik sekali. Pengujian ini memberi indikasi bahwa algoritma yang diterapkan untuk mengenali objek sampai dengan mendeteksi arah tunjuk dari isyarat jari sudah berjalan dengan baik. Penghitungan sudut cosinus dan metode lain dalam program membuahkan hasil, semakin kompleks dan unik suatu cara pendeteksian, maka hasilnya juga akan semakin tepat, tidak hanya berdasarkan warna dari sarung tangan, tapi juga pengaruh dari arah tunjuk dan jarak antara tangan dengan kamera.

Selain dengan kondisi normal, dilakukan juga pengujian dengan kondisi lain, misalkan ujung jari ada lebih dari 1 . Hasil dari percobaan tersebut didapatkan, maksimal ujung jari yang bisa untuk menggerakkan lengan adalah 2 ujung jari terdeteksi, itupun hasilnya kurang stabil. Jika jari yang terdeteksi lebih dari 2, maka sistem tidak mengenalinya sebagai isyarat menggerakkan lengan robot, hal ini karena sudut dari vektor-vektor di ujung jari nilainya terlalu besar.

\section{KESIMPULAN}

Dari penelitian yang telah dilakukan, dapat diambil kesimpulan sebagai berikut:

1. Dengan purwarupa sistem kendali penelitian ini, dokter gigi tidak perlu menyentuh langsung dental light dalam mengontrol gerakannya.

2. Metode yang diterapkan untuk mengenali objek dengan memilah warna dengan latar belakangnya sudah berjalan dengan baik. 
3. Semakin kompleks dan unik suatu cara pendeteksian, maka hasilnya juga akan semakin tepat, tidak hanya berdasarkan warna dari sarung tangan, tapi juga pengaruh dari arah tunjuk dan jarak antara tangan dengan kamera.

4. Metode erosi dan dilasi dapat digunakan untuk membuang derau berupa titik-titik (salt and pepper noise).

5. Dari 4 warna sarung tangan yang diuji, warna kuning adalah warna terbaik.

6. Intensitas cahaya mempengaruhi baik buruknya kualitas citra yang dapat ditangkap kamera. Kualitas citra yang baik didapat dari intensitas cahaya yang tidak terlalu rendah atau terlalu tinggi.

7. Jarak tangan terhadap webcam yang terbaik adalah $55-65 \mathrm{~cm}$.

8. Waktu respon dari lengan robot untuk bergerak setelah ada isyarat jari terhitung baik, yaitu rata-rata antara $0,4-0,6$ sekon.

9. Ketepatan dari gerakan lengan robot sudah baik sekali dan hasilnya maksimal jika jari yang terdeteksi hanya 1.

\section{SARAN}

Beberapa saran dari penulis untuk pengembangan kendali lengan dental light dengan isyarat jari ini antara lain :

1. Gerakan dari lengan robot dibuat agar bisa bergerak lebih dari satu motor servo pada waktu yang sama. Karena sementara ini hanya bisa satu motor servo tiap satu waktu.

2. Algoritma pengolahan citra dapat dibuat lebih efisien lagi dan diberi pengalokasian memori yang dipakai, hal ini agar pengolahan citra dapat dilakukan dengan cepat namun tidak memakai resource banyak dari komputer/laptop.

3. Metode pendeteksian isyarat dibuat agar dapat bekerja dengan baik dengan pengaruh intensitas cahaya beragam dan warna latar belakang yang sama dengan warna objek yang ingin dikenali.

4. Sistem kendali dibuat dengan RTOS (real time operating system) agar penggunaan chip-nya seifisien dan sesedikit mungkin.

5. Menggunakan komponen regulator tegangan yang relatif tahan panas agar perangkat keras dapat bertahan bekerja dalam jangka waktu yang lama.

\section{DAFTAR PUSTAKA}

[1]. Kabdental.com, 2011, Operatory Light, http://kabdental.com/small-dentalequipment/lighting-reflectors-shields/beaverstate.htm, diakses pada 6 Maret 2012.

[2]. Davies, E.R., 2005, Machine Vision Theory Algorithms Practicalities, Morgan Kaufmann, London.

[3]. Agrawal, K., 2012, Final Project Snap, http://golancourses.net/2012spring/05/10/ kaushalagrawal-final-project-snap/, diakses pada 10 Juni 2012.

[4]. Ho, L., 2011, Finger Detection and Gesture Recognition, http://code.google.com/ p/fingerdetection-and-gesture-recognition/, diakses pada 4 Maret 2012.

[5]. Object Development, 2008, PowerSwitch, www.obdev.at/products/vusb/ powerswitch.html. Diakses pada 6 Maret 2012.

[6]. usamedicalgloves.com, 2012, Gloves By Color, http://www.usamedicalgloves.com/ colored-medical-gloves. Diakses pada 23 Juli 2012.

IJEIS Vol. 2, No. 1, April 2012 : $45-56$ 